\title{
ĐÁNH GIÁ SƯ TíCH TỤ Pb CỦA MỘT Số LOÀ ỐC DÙNG LÀM THỰC PHẨM ĐƯợC KHAI THÁC Ở SÔNG HƯđ̛́NG THÀNH PHỐ HUẾ
}

\author{
Nguyễn Minh Trí ", Nguyễn Việt Thắng, Võ Đình Ba
}

Truờng Đại học Khoa học, Đại học Huế

(Ngày đến tòa soạn: 30/6/2019; Ngày sủa bài sau phản biện: 11/9/2019;

Ngày chấp nhận đăng: 20/9/2019)

\section{Tóm tắt}

Ở thành phố Huế, một số loài ốc được chế biến thành các món ăn đặc trưng được nhiều người ưa chuộng. Tuy nhiên một số nghiên cứu trên thế giới đã chỉ ra rằng nhóm động vật này có thể tích tụ các kim loại nặng trong cơ thể chúng với hàm lượng cao hơn nhiều lần so với ở môi trường bên ngoài nên làm cho chúng trở thành độc hại với sức khỏe người sử dụng. Kết quả khảo sát 04 loài ốc Bellamya filosa, Sulcospira proteu, Pomacea canaliculata, Pila conia được khai thác ở sông Hương để sử dụng làm thực phẩm cho thấy chúng có hàm lượng kim loại $\mathrm{Pb}$ ở mức cao và vượt tiêu chuẩn cho phép của Bộ Y tế (QCVN 8-2:2011/BYT) nên không đảm bảo an toàn cho người sử dụng. Chỉ số đánh giá rủi ro ô nhiễm của $\mathrm{Pb}$ đối với sức khỏe khi sử dụng các loài ốc này ở mức cao, sẽ ảnh hưởng xấu đến sức khỏe của người sử dụng.

Tù khóa: Ốc, kim loại chì, tích lũy sinh học, rủi ro súc khỏe.

\section{1. ĐẠTT VẤN ĐỀ}

Ngày nay ngộ độc thực phẩm do nhiễm kim loại đã được quan tâm nhiều hơn bởi những tác hại khôn lường của kim loại đối với sức khỏe người tiêu dùng. Hiện tại có nhiều nguyên tố kim loại nặng có thể là nguồn gây ô nhiễm thực phẩm, trong đó những nguyên tố được nhắc đến nhiều nhất là chì, thủy ngân, thạch tín... Ăn phải thực phẩm nhiễm chì vượt quá hàm lượng cho phép, người sử dụng có nguy cơ bị ngộ độc và có thể gây ảnh hưởng xấu đến nhiều bộ phận trong cơ thể như suy thận, gây phù não... Chì gây ngộ độc cho cơ thể rất nặng nề, lâu dài và hay tái phát do thời gian đào thải là rất lâu.

Ở Việt Nam, các loài ốc là những loài được chế biến thành nhiều món ăn đặc trưng được nhiều người ưa chuộng. Tuy nhiên, việc nghiên cứu về sự tích lũy kim loại nặng trong nhóm động vật nhuyễn thể thân mềm này vẫn chưa được quan tâm nhiều. Trong nghiên cứu này, chúng tôi giới thiệu một số kết quả về sự tích lũy kim loại chì $(\mathrm{Pb})$ của 04 loài ốc sống ở sông Hương, thành phố Huế đã được người dân khai thác làm thực phẩm.

\section{PHƯƠNG PHÁP NGHIÊN CÚU}

- Các loài ốc và mẫu trầm tích được thu tại khu vực từ cồn Hến đến cồn Dã Viên ở sông Hương, thành phố Huế bằng gàu đáy Petersen vào đợt 1 tại cồn Hến (tháng 10/2018) và đợt 2 tại cồn Dã Viên (tháng 4/2019).

- Các loài ốc được phân loại bằng hình thái so sánh theo khóa lưỡng phân của Đặng Ngọc Thanh [5].

- Mẫu ốc được tách lấy phần thịt và sấy ở nhiệt độ $100^{\circ} \mathrm{C}$ cho đến khô hoàn toàn, mẫu trầm tích được loại bỏ các tạp chất, hong khô trong không khí ở nhiệt độ phòng. Các loại mẫu được 
nghiền nhỏ bằng máy nghiền đồng thể và bảo quản trong bình hút ẩm.

- Hóa chất: các hóa chất tinh khiết của hãng Merck.

- Vô cơ hóa các loại mẫu bằng hỗn hợp $\mathrm{H}_{2} \mathrm{SO}_{4}$ và $\mathrm{HNO}_{3}$ theo TCVN 7602:2007, pha loãng dung dịch vô cơ này bằng nước cất 2 lần để phân tích hàm lượng kim loại $\mathrm{Pb}$ bằng phương pháp quang phổ hấp thụ nguyên tử AAS (Atomic Absorption Spectrometers) trên máy Analyst 800 của hãng Perkin Elmer - USA [6].

- Xác định hệ số tích lũy sinh học BSAF (Biota-sendiment accumulation factor) [9] theo công thức:

- Xác định hệ số rủi ro sức khỏe RQ (risk quotient) theo công thức:

$$
\mathrm{BSAF}=\frac{\text { Hàm lượng kim loại trong mẫu }(\mathrm{mg} / \mathrm{kg})}{\text { Hàm lượng kim loại trong trầm tích }(\mathrm{mg} / \mathrm{kg})}
$$

Mức độ rủi ro sức khỏe đối với con người được đánh giá như sau:

$$
\mathrm{BSAF}=\frac{\text { Hàm lượng kim loại trong mẫu }(\mathrm{mg} / \mathrm{kg})}{\text { Hàm lượng kim loại trong trầm tích }(\mathrm{mg} / \mathrm{kg})}
$$

RQ: $0,01-0,1$ : rủi ro thấp

$\mathrm{RQ}>1$ : rủi ro cao
RQ: $0,1-1$ : rủi ro trung bình

$\mathrm{RQ}>100$ : rủi ro rất cao [7].

Các số liệu được xử lý theo phương pháp thống kê, so sánh các giá trị trung bình theo phân tích Anova với mức ý nghĩa $\alpha=0,05$ bằng chương trình Microsoft Excel.

\section{KẾT QUẢ VÀ BÀN LUẬN}

\section{1. Định danh các loài ốc được khai thác hàng ngày dùng làm thực phẩm}

Qua quá trình thu mẫu chúng tôi bắt gặp 4 loài ốc thường được khai thác trên sông Hương và bán phổ biến cho người dân dùng làm thức ăn có tên thường gọi như sau: ốc Hút, ốc Quắn, ốc Bưu sông và ốc Bưu vàng (nhiều nơi gọi là ốc Bươu). Kết quả xác định tên khoa học của 4 loài ốc sống tại sông Hương ở thành phố Huế được thể hiện ở các hình sau:

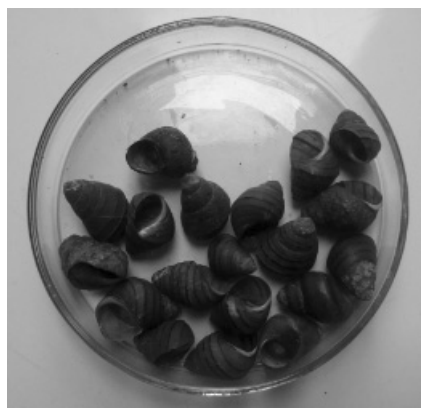

Hình 1. Ôc Hút (Bellamya filosa Reev)

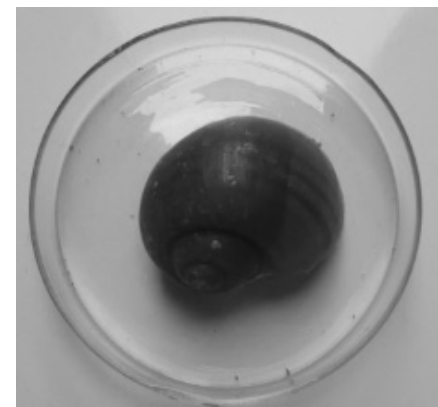

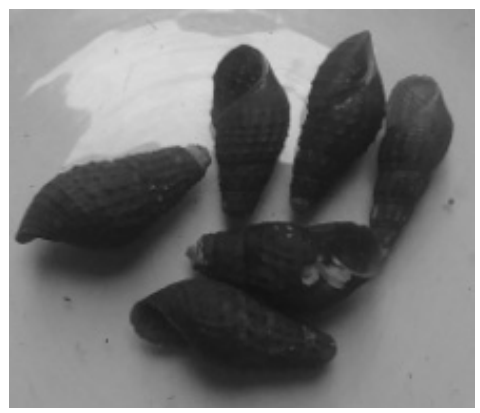

Hình 2. Ôc Quắn (Sulcospira proteus Bavaxy)

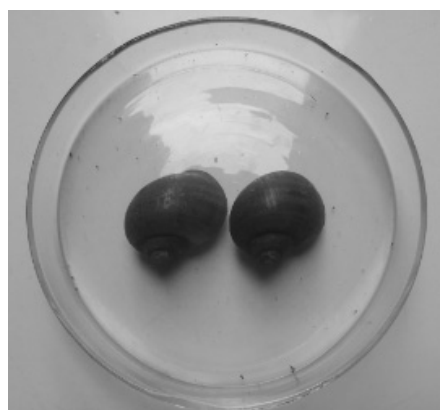

Hinh 3. Ốc Bư vàng (Pomacea canaliculata Lamarck) Hình 4. Ốc Bưu sông (Pila conia Gray) 
Kết quả định danh các loài này phù hợp với kết quả nghiên cứu đã công bố về thành phần loài động vật đáy sống ở sông Hương của các tác giả Võ Văn Phú (2011) [3] và Hoàng Đình Trung (2013) [8]. Qua khảo sát ở những người đi khai thác và mua bán, chúng tôi nhận thấy số lượng các loài được khai thác theo thứ tự nhiều lên như sau: ốc Hút, ốc Bưu vàng, ốc Quắn, ốc Bưu sông.

\subsection{Hàm lượng $\mathrm{Pb}$ trong mẫu sinh vật và trầm tích sông}

Sự tích lũy kim loại trong các đối tượng thủy sản chịu sự ảnh hưởng của các yếu tố thức ăn và môi trường sống. Chính vì vậy, để có cơ sở đánh giá nguồn ô nhiễm và sự tích lũy kim loại nặng trong các loài ốc, chúng tôi đã tiến hành phân tích hàm lượng $\mathrm{Pb}$ trong trầm tích và thịt của chúng, kết quả được thể hiện ở bảng 1 .

Bảng 1. Hàm lượng $\mathrm{Pb}(\mathrm{mg} / \mathrm{kg}$ ) trong mẫu ốc và trầm tích sông Hương (tính theo khối lượng khô)

\begin{tabular}{|l|c|c|}
\hline \multicolumn{1}{|c|}{ Thò̀i gian } & Oột 1 & Đọt 2 \\
\hline Ốc Hút (Bellamya filosa Reev) & $1,845 \pm 0,007$ & $1,849 \pm 0,002$ \\
\hline Ốc Quắn (Sulcospira proteus Bavaxy) & $1,673 \pm 0,006$ & $1,679 \pm 0,002$ \\
\hline Ốc Bưu vàng (Pomacea canaliculata Lanmarck) & $1,732 \pm 0,002$ & $1,733 \pm 0,003$ \\
\hline Ốc Bưu sông (Pila conia Gray) & $2,486 \pm 0,002$ & $2,489 \pm 0,004$ \\
\hline Trầm tích & $15,896 \pm 0,011$ & $16,104 \pm 0,013$ \\
\hline
\end{tabular}

Kết quả ở bảng 1 cho thấy: $\mathrm{Pb}$ có tồn tại trong môi trường trầm tích là nơi sống chủ yếu của các loài ốc hến ở sông Hương với hàm lượng rất cao, tại khu vực cồn Hến là $15,596 \mathrm{mg} / \mathrm{kg}$ và khu vực cồn Dã Viên là $16,204 \mathrm{mg} / \mathrm{kg}$. Trong đó nền đáy ở khu vực cồn Dã Viên có hàm lượng $\mathrm{Pb}$ cao hơn, có lẽ ở khu vực này chịu tác động của nước thải từ làng nghề đúc đồng ở Phường Đúc có chứa một lượng $\mathrm{Pb}$ được thải ra sông Hương mà chưa qua xử lý. Kết quả này cho thấy các kim loại $\mathrm{Pb}$ sau khi đi vào sông hồ thì được lắng đọng ở các lớp trầm tích của sông. Điều này là phù hợp với kết quả nghiên cứu về hàm lượng $\mathrm{Pb}$ trong nền đáy có các loài thân mềm sinh sống của một số tác giả như Phạm Kim Phương (2007) [4] và Nguyễn Văn Khánh (2010) [2].

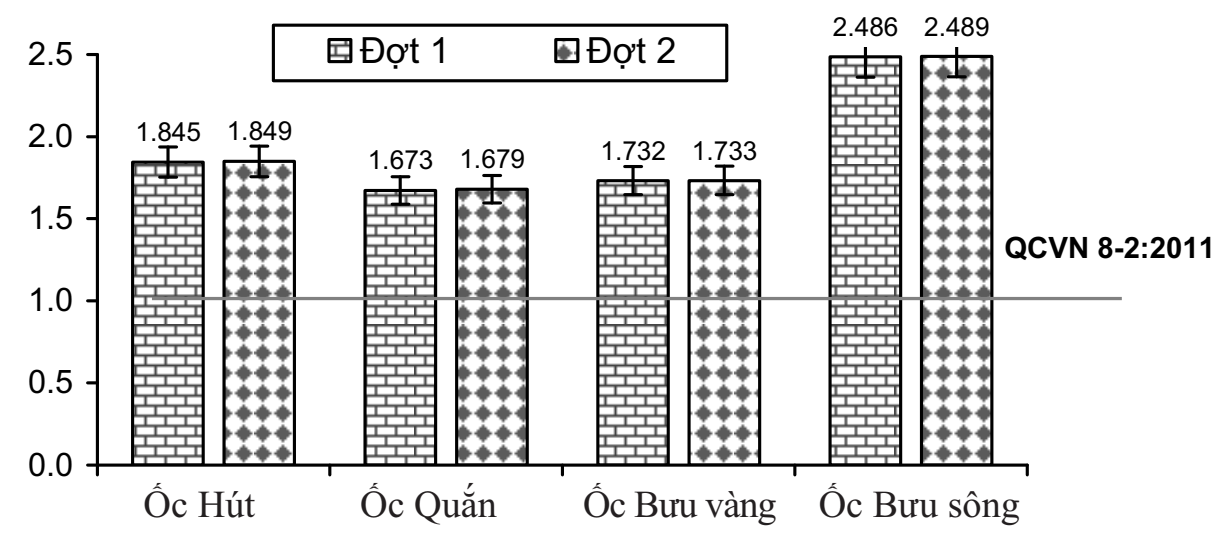

Hình 5. Hàm lượng Pb trong các loài ốc sống ở sông Hưong

Nhìn chung hàm lượng $\mathrm{Pb}$ có trong thịt của các loài ốc sống ở các khu vực khác nhau không có sự chênh lệch nhiều (hình 5). Khi so sánh kết quả phân tích về hàm lượng $\mathrm{Pb}$ ở trong các loài ốc với tiêu chuẩn về giới hạn kim loại nặng trong thực phẩm theo QCVN 8-2:2011/BYT là $1 \mathrm{mg} / \mathrm{kg}$ [1] cho thấy hầu hết các mẫu ốc đều vượt giới hạn cho phép dùng để làm thực phẩm cho con người. 
Cụ thể hàm lượng $\mathrm{Pb}$ vượt quá giới hạn cho phép như sau:

- Ốc Hút (Bellamya filosa Reev): vượt 1,845 - 1,849 lần

- Ốc Quắn (Sulcospira proteus Bavaxy): vượt 1,673 - 1,679 lần

- Ốc Bưu vàng (Pomacea canaliculata Lamarck): vượt 1,732 - 1,733 lần

- Ốc Bưu sông (Pila conia Gray): vượt 2,486 - 2,489 lần

Qua kết quả trên có thể thấy rằng phần lớn hàm lượng $\mathrm{Pb}$ phân tích được đều vượt quá giới hạn cho phép của $\mathrm{B}$ ọ $\mathrm{Y}$ tế cho phép từ $1-1,5$ lần. Nhìn chung hàm lượng $\mathrm{Pb}$ trong các mẫu động vật nhuyễn thể ở 02 khu vực khảo sát trên sông Hương đều cao hơn giới hạn do Bộ Y tế quy định cho việc sử dụng các loài ốc dùng làm thực phẩm là $1,0 \mathrm{mg} / \mathrm{kg}$ và thay đổi rất ít giữa 2 địa điểm. Vì vậy, không nên sử dụng các loài ốc sống ở 02 địa điểm này của sông Hương làm thực phẩm thường xuyên.

\section{Hệ số tích lũy $\mathrm{Pb}$ của các loài ốc và rủi ro sức khỏe đối với người sử dụng}

Hầu hết các kim loại nặng thường khó phân hủy trong môi trường và chúng tồn tại ở tầng sâu như nước tầng đáy và trầm tích ở sông, hồ... nên nguy cơ nhiễm kim loại vào các đối tượng thủy sản là rất cao, qua đó sẽ dẫn đến tích lũy sinh học và ảnh hưởng đến sức khỏe cộng đồng thông qua chuỗi thức ăn. Trong nghiên cứu này, chúng tôi sử dụng hệ số tích lũy sinh học (BSAF) để thấy được khả năng tích lũy $\mathrm{Pb}$ của các loài ốc sống ở khu vực sông Hương (hình 6).

BSAF

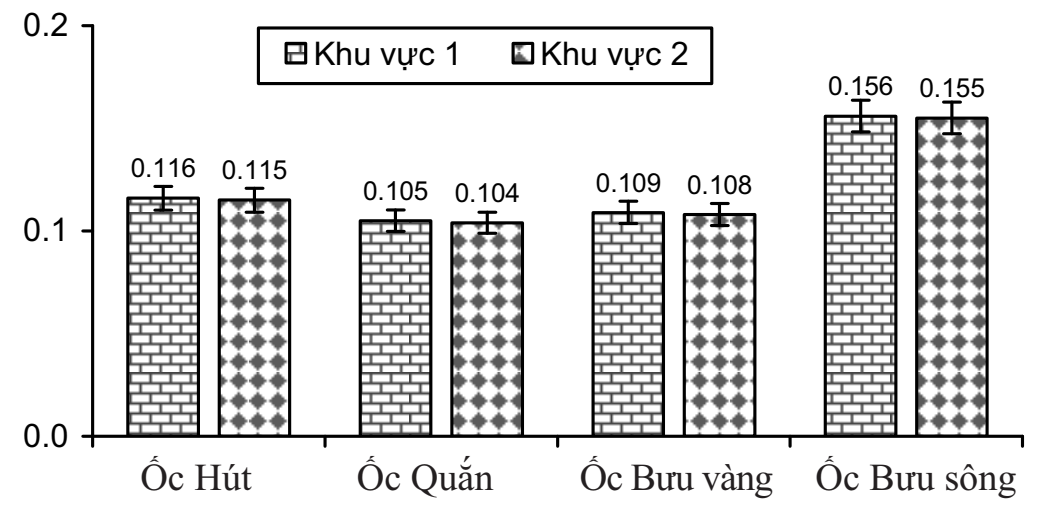

Hình 6. Hệ số tích lũy Pb của các loài ốc sống ở sông Hưong

Kết quả phân tích $\operatorname{ANOVA}(\alpha=0,05)$ cho thấy mức độ tích lũy $\mathrm{Pb}$ ở loài ốc Bưu sông là cao nhất và có sự khác nhau có ý nghĩa so với các loài còn lại.

Đánh giá mức độ rủi ro về sức khỏe là đánh giá về mức độ nguy hại tiềm tàng ảnh hưởng đến sức khỏe của con người từ các chất độc hại. Mức độ về nguy cơ rủi ro của $\mathrm{Pb}$ ảnh hưởng đến sức khỏe của con người thông qua hệ số RQ để đánh giá được tính toán và trình bày ở bảng 2 .

Bảng 2. Hệ số rủi ro sức khỏe đối với người sử dụng

\begin{tabular}{|l|c|c|}
\hline \multicolumn{1}{|c|}{ Thò̀i gian } & Đọt 1 & Đột 2 \\
\hline Ốc Hút (Bellamya filosa Reev) & 1,845 & 1,849 \\
\hline Ốc Quắn (Sulcospira proteus Bavaxy) & 1,673 & 1,679 \\
\hline Ốc Bưu vàng (Pomacea canaliculata Lanmarck) & 1,732 & 1,733 \\
\hline Ốc Bưu sông (Pila conia Gray) & 2,486 & 2,489 \\
\hline
\end{tabular}


Kết quả ở bảng 2 cho thấy mức độ rủi ro của $\mathrm{Pb}$ ở các loài ốc được khảo sát đều ở mức rủi ro cao $(\mathrm{RQ}>1)$. Pb là nguyên tố không cần thiết cho cơ thể, hàm lượng $\mathrm{Pb}$ quá cao sẽ gây ra các bệnh thiếu máu, hỏng thận, những bệnh của hệ thần kinh như mất khả năng điều hòa cơ thể, giảm chức năng vận động và trí tuệ kém phát triển... Như vậy trong thịt của các loài ốc được khảo sát có hàm lượng $\mathrm{Pb}$ vượt giới hạn cho phép từ 1,673 - 2,489 lần. Vì vậy cần hạn chế sử dụng các loài này làm thực phẩm để đảm bảo sức khỏe con người.

\section{KẾT LUẬn}

Từ những kết quả nghiên cứu trên, chúng tôi rút ra một số kết luận sau:

Các loài ốc Bellamya filosa, Sulcospira proteu, Pomacea canaliculata, Pila conia được khảo sát ở khu vực sông Hương có hàm lượng $\mathrm{Pb}$ ở mức cao và vượt tiêu chuẩn cho phép của Bộ $\mathrm{Y}$ tế nên không đảm bảo an toàn cho người sử dụng.

Sự tích lũy $\mathrm{Pb}$ ở loài ốc Bưu sông (Pila conia Gray) là cao nhất và khác nhau có ý nghĩa so với các loài còn lại.

Hệ số đánh giá rủi ro của $\mathrm{Pb}$ đối với sức khỏe khi sử dụng các loài này ở mức cao, sẽ gây nguy hiểm cho người sử dụng.

\section{TÀI LIẸU THAM KHẢO}

1. Bộ Y tế (2011). QCVN 8-2:2011/BYT. Quy chuẩn kỹ thuật quốc gia đối với giới hạn ô nhiễm kim loại nặng trong thực phẩm.

2. Nguyễn Văn Khánh, Võ Văn Minh, Phạm Thị Hồng Hà, Dương Công Vinh (2010), "Hàm lượng $\mathrm{As}, \mathrm{Pb}$ tích lũy trong loài Hến (Corbicula sp.) và Hàu sông (Ostrea rivularis Gould, 1861) tại cửa sông $\mathrm{Cu}$ Đê, thành phố Đà Nẵng", Tạp chi Khoa học và Công nghệ Biển, Tập 10 Số 1, 27-35

3. Võ Văn Phú. Hoàng Đình Trung. Lê Thị Miên Ngọc (2011), "Đa dạng thành phần loài động vật không xương sống cỡ lớn và chất lượng nước mặt ở sông Hương”, Tạp chí Nghiên ciúu và Phát triển Thù̀a Thiên Huế, 5 (88), 89-96

4. Phạm Kim Phương, Nguyễn Thị Dung, Chu Phạm Ngọc Sơn (2007), "Nghiên cứu sự tích lũy kim loại nặng $\mathrm{As}, \mathrm{Cd}, \mathrm{Pb}$ và $\mathrm{Hg}$ từ môi trường nuôi tự nhiên lên nhuyễn thể hai mảnh vỏ", Tạp chi Khoa học và Công nghệ, 5 (45), 57-62

5. Đặng Ngọc Thanh, Hồ Thanh Hải (2001), "Giáp xác nước ngọt. Động vật chí Việt Nam”, Tập 5. NXB Khoa học và Kỹ thuật.

6. TCVN 7602:2007. Thực phẩm - Xác định hàm lượng chì bằng phương pháp quang phổ hấp thụ nguyên tử.

7. Lê Thị Hồng Trân (2008), "Đánh giá rủi ro môi trường”, NXB Khoa học Kỹ thuật.

8. Hoàng Đình Trung, Đoàn Việt Quốc (2013), "Kết quả nghiên cứu bước đầu về thành phần loài thân mềm hai mảnh vỏ (bivalvia) và chân bụng (gastropoda) ở sông Hương thành phố Huế", Tuyển tập Báo cáo Hội nghị Sinh thái và Tài nguyên Sinh vật lần thứ V. 794-800

9. Lawrence Burkhard (2009, "Estimation of biota sediment accumulation factor (BSAF) from paired observations of chemical concentrations in biota and sediment", US. Environmental Protection Agency. 


\section{Summary}

\section{LEAD ACCUMULATION IN SOME SNAILS USED AS FOOD AT HUONG RIVER, HUE CITY}

\section{Nguyen Minh Tri, Nguyen Viet Thang, Vo Dinh Ba \\ University of Science, Hue University}

In Hue City, several river snails are popularly processed into dishes. However, former studies have proved that this group of animals can accumulate heavy metals in their bodies at much higher levels than in the external environment, making them harmful to consumers' health. Results indicated that lead contents in four species including Belaya filosa, Sulcospira proteu, Pomacea canaliculata, and Pila conquered exploited in Huong river for use as food exceeded the permitted level issued by The Ministry of Health (QCVN 8-2 : 2011/BYT). The human health risk assessment for lead exposure showed high potential risks to consumers. The risk quotation (RQs) is higher than one suggested that it is unsafe to consume these snails.

Keywords: Lead, snails, human health risk. 